\title{
Roles for the FCRL6 Immunoreceptor in Tumor Immunology
}

Randall S. Davis*

Departments of Medicine, Microbiology, and Biochemistry \& Molecular Genetics, The Comprehensive Cancer Center, University of Alabama at Birmingham, Birmingham, AL, United States

Members of the Fc receptor-like (FCRL1-6) gene family encode transmembrane glycoproteins that are preferentially expressed by $\mathrm{B}$ cells and generally repress responses via cytoplasmic tyrosine-based regulation. Given their distribution and function, there is a growing appreciation for their roles in lymphoproliferative disorders and as immunotherapeutic targets. In contrast to FCRL1-5, FCRL6 is distinctly expressed outside the $\mathrm{B}$ lineage by cytotoxic $\mathrm{T}$ and NK lymphocytes. Its restricted expression by these orchestrators of cell-mediated immunity, along with its inhibitory properties and extracellular interactions with MHCII/HLA-DR, represent a newly appreciated axis with relevance in tolerance and cancer defense. The significance of FCRL6 in this arena has been recently demonstrated by its upregulation in $\mathrm{HLA}-\mathrm{DR}^{+}$tumor samples from melanoma, breast, and lung cancer patients who relapsed following PD-1 blockade. These findings imply a potential mechanistic role for FCRL6 in adaptive evasion to immune checkpoint therapy. Here we review these new developments in the FCRL field and identify new evidence for the prognostic significance of FCRL6 in malignancies that collectively indicate its potential as a biomarker and therapeutic target.

Ali A. Zarrin,

TRex Bio, United States

Reviewed by:

Andreas Pircher,

Innsbruck Medical University, Austria Nahum Puebla-Osorio,

University of Texas MD Anderson

Cancer Center, United States

*Correspondence: Randall S. Davis rsdavis@uab.edu

Specialty section:

This article was submitted to Cancer Immunity and Immunotherapy,

a section of the journal

Frontiers in Immunology

Received: 22 June 2020 Accepted: 01 September 2020 Published: 14 October 2020

Citation:

Davis RS (2020) Roles for the FCRL6 Immunoreceptor in Tumor Immunology.

Front. Immunol. 11:575175.

doi: 10.3389/fimmu.2020.575175
Keywords: lymphocytes, inhibitory signaling, regulation, tumor immunology, cell-mediated immunity, FCRL family

\section{INTRODUCTION}

The immune system maintains a careful balance of activation vs. inhibition signals to coordinate restraint at homeostasis and promote effector responses when triggered. These cellular mechanisms establish tissue surveillance and stand ready to mount a vigorous immune defense, but must also suppress overzealous responses that could potentially harm the host. The growing significance of inhibitory receptors in immune regulation and human health is underscored by their roles in a variety of disorders including infectious diseases, autoimmunity, and cancer.

The discovery that malignancies have evolved mechanisms that exploit inhibitory receptors to circumvent elimination by immune cells is fundamentally impacting our understanding of tumor immunology and revolutionizing cancer therapy. Antibody (Ab)-mediated targeting of the PD-1/PD-L1 and CTLA-4/B7 immune checkpoint inhibitor (ICI) axes enables disruption of receptor-ligand interactions that shield tumors from infiltrating cytotoxic lymphocytes $(1,2)$. This selective approach has reinvigorated the field of tumor immunology and ignited extraordinary potential for new diagnostic, prognostic, and therapeutic strategies that deliver more targeted and effective patient care. As of 2018 , it is estimated that $\sim 44 \%$ of cancer patients are eligible for ICI therapy (3). However, as treatment expands, many patients who enjoyed durable responses will relapse as the tumor adapts and becomes resistant to recognition and rejection by tumor infiltrating lymphocytes (TILs) $(4,5)$. Unfortunately, the mechanisms responsible for ICI resistance remain incompletely defined. This issue is becoming a growing barrier for cancer patients who have limited therapeutic options and require alternative strategies to overcome the tumor's adaptive resistance. 
Here we review recent developments related to members of the Fc receptor-like (FCRL1-6) immunoregulatory family with a specific focus on the FCRL6 molecule in cellmediated immunity and its newly appreciated roles in tumor immunology. Its restricted expression by cytotoxic NK and $\mathrm{T}$ cells, cytoplasmic tyrosine-based inhibitory properties, and extracellular interactions with MHCII/HLA-DR introduce a new axis with relevance in tolerance and cancer defense (Figure 1). Its importance was recently demonstrated in studies that identified its upregulation in HLA-DR ${ }^{+}$tumor samples from melanoma, breast, and lung cancer patients who had relapsed following PD1 blockade (7). These findings imply a potential mechanistic role for FCRL6 in adaptive evasion to ICI therapy. By investigating its expression among The Cancer Genome Atlas (TCGA) tumor samples, we identify new evidence for the prognostic significance of FCRL6 in melanoma, breast, and lung cancer that collectively indicate its potential as a biomarker and therapeutic target.

\section{FC RECEPTOR-LIKE MOLECULES (FCRL) IN B CELL REGULATION}

An extended family of FCRL1-6 genes in humans and mice encode type I transmembrane (TM) glycoproteins with cytoplasmic immunoreceptor tyrosine-based activation (ITAM)like or inhibitory (ITIM) motifs [reviewed in $(8,9)$ ]. FCRL1-5 are preferentially expressed by $\mathrm{B}$ lineage cells and modulate $\mathrm{B}$ cell antigen-receptor (BCR)-mediated signaling (10). Notably, FCRL3 is also detected outside the $\mathrm{B}$ lineage on subsets of $\mathrm{T}$ and NK cells (11-13). While FCRL1 is a pan B cell marker with ITAM-like motifs that promotes BCR activation in humans and mice [unpublished studies and (14-16)], signaling studies demonstrate that FCRL2-5 generally exert inhibitory function. Consistent with their possession of cytoplasmic ITIM sequences, following BCR cross-linking, FCRL2-5 are tyrosine phosphorylated $(\mathrm{pY})$ and can repress global $\mathrm{pY}, \mathrm{Ca}^{2+}$ flux, and MAP kinase activation via recruitment of the SHP-1 and/or SHP-2 phosphatases (17-21). In mice (m), mFCRL5 has similar inhibitory properties (22). However, the presence of both ITAM and ITIM in the FCRL2 -5 representatives implies more complex signaling than the classical FCRs that are either activating or inhibitory (23). Accordingly, mFCRL5 has the ability to modulate BCR signaling in a binary fashion. However, its functional properties among B cell subsets vary according to the differential recruitment of the Lyn Src-family kinase (SFK) to an ITAM-like sequence and SHP-1 to an ITIM (21). The capacity for composite activating and inhibitory signaling is also present in human FCRL3 and FCRL4. These proteins possess dual regulatory properties that appear to differ according to the innate (Tolllike receptor/TLR) or adaptive (BCR) nature of B cell stimulation $(24,25)$. Molecular dissection of the FCRL4 cytoplasmic tail has demonstrated that its function is altered by the recruitment of at least two different SFKs. FCRL4 wields suppressive activity in B cells co-expressing FGR, but promotes activation in B cells co-expressing HCK p59 (26). Thus, as opposed to the classical FCR for IgG and IgE, these findings highlight that many FCRLs possess multifaceted regulatory potential.
Beyond their intracellular signaling capability, ligands have been identified for several FCRLs. The potential for Ig binding was initially detected for FCRL4 and FCRL5, but was confirmed in studies by Wilson et al. who found these receptors could interact with $\operatorname{IgA}$ and $\operatorname{IgG}(27,28)$. However, unlike the classical IgG and IgE FCRs, IgG binding to FCRL5 is glycosylation dependent and requires both the Fab and Fc portions (29). Recent work has also identified secretory IgA as a ligand for FCRL3 and this relationship could impact inhibition in $\mathrm{T}$ regulatory cells (30). How these receptor-ligand interactions influence the systemic and cellular function of the lymphocytes that express them or contribute to disease pathogenesis remains ripe for future investigation.

\section{RELEVANCE OF FCRL1-5 IN B CELL LYMPHOPROLIFERATIVE DISORDERS}

The preferential expression of FCRL1-5 by B cells has made these molecules relevant clinical candidates in lymphoproliferative disorders such as leukemias and lymphomas. In fact their initial identification by the Dalla-Favera group as immunoglobulin superfamily receptor translocation-associated (IRTA) genes, resulted from the characterization of a $\mathrm{t}(1 ; 14)(\mathrm{q} 21 ; \mathrm{q} 32)$ translocation breakpoint in a multiple myeloma cell line (28). These early studies also demonstrated dysregulated FCRL5/IRTA2 transcript expression in follicular lymphoma and myeloma cell lines with 1q21 abnormalities (31). Variable upregulation of FCRL1-5 in B cell malignancies was further revealed through the Lymphochip-based microarray analyses led by the Staudt group (32), but have now been expanded in ever-growing numbers of high-throughput RNA-seq studies. Following the development of monoclonal Abs (mAbs), several groups validated FCRL surface protein expression by malignant $\mathrm{B}$ cell lines as well as B cell chronic lymphocytic leukemia (CLL) cells, the most common leukemia in Western countries $(11,33,34)$. An analysis of FCRL1-5 in a cohort of CLL patients well-characterized for standard prognostic factors, identified FCRL2 as a marker for a subgroup of CLL patients with a more indolent disease course as reflected by favorable progression free survival and overall survival $(34,35)$. By flow cytometry, FCRL2 was able to segregate CLL samples according to the mutation status of the $I G H V$ gene expressed by the leukemic clone. Its upregulation by mutated IGHV CLL samples introduced a novel surface marker of this favorable disease subtype. This pattern of FCRL2 expression was in contrast to CD38, ZAP-70, and CD49d, which are chiefly upregulated in patients with unmutated CLL who experience a more aggressive disease course $(10,36,37)$. The inhibitory function evident for FCRL2 in healthy B cells (19) implies that its upregulation by indolent $I G H V$ mutated CLL might also contribute to biological suppression in this favorable CLL subtype. Thus, the expression of these regulatory proteins may not only have prognostic significance, but could also have physiological impact on the clinical disease course and pathogenesis of certain lymphoproliferative disorders.

The targetability of FCRL members in B cell malignancies is an area of active investigation and FCRL5 has become a promising 


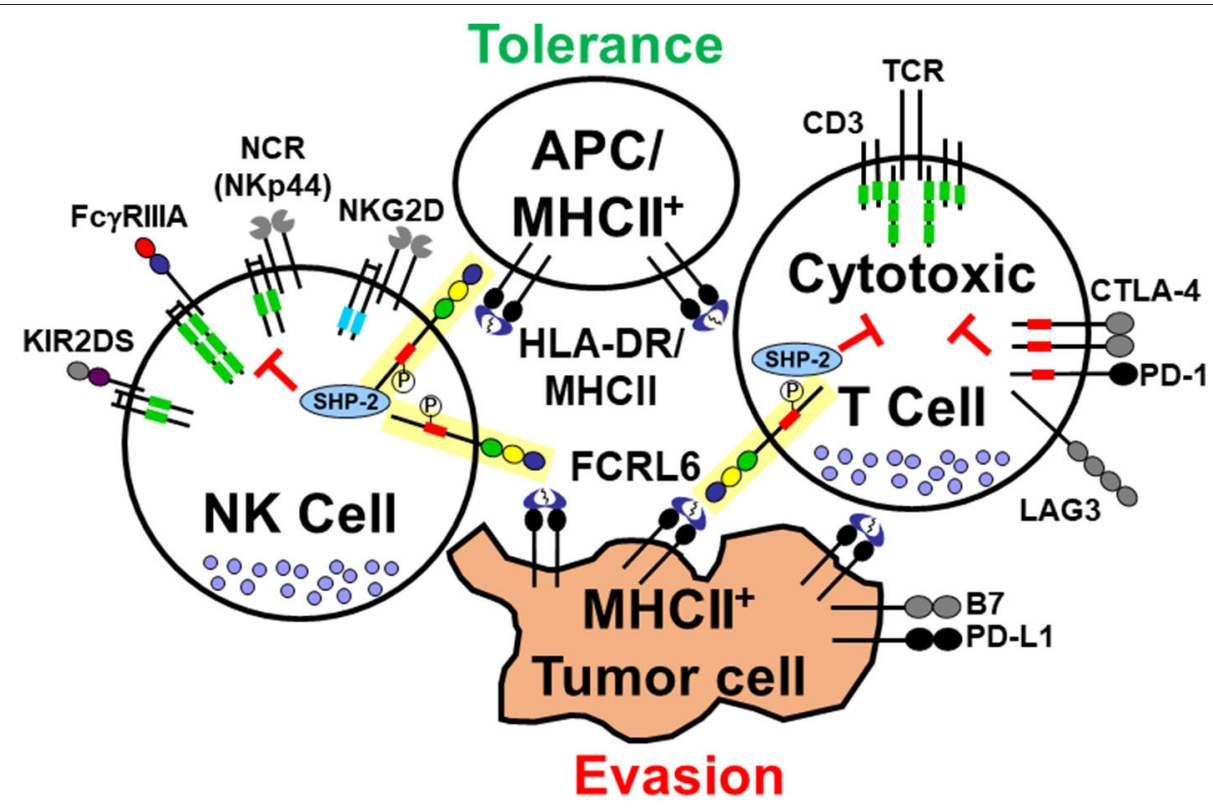

FIGURE 1 | Interactions of the cytotoxic lymphocyte-expressed FCRL6 immunoreceptor with MHCII-expressing cells. The schematic representation shows the FCRL6 receptor (yellow box), which is composed of three extracellular Ig-like domains, an uncharged transmembrane region, and a cytoplasmic tail with two tyrosines, including a consensus ITIM (red rectangle) that recruits the SHP-2 tyrosine phosphatase. FCRL6 is expressed by cytotoxic T and NK cells and has been found to interact with $\mathrm{MHCl} / \mathrm{HLA}-\mathrm{DR}$. Other pertinent adaptor-associated activating (ITAM-bearing, green rectangles and DAP-10, blue rectangles) and immune checkpoint inhibitory (ICI) molecule pairs (CTLA-4/B7, PD-1/PD-L1, LAG3/MHCII, and NKp44/MHCII) highlight the regulatory balance of immune tolerance and tumor evasion between cytotoxic lymphocytes and APCs or tumor cells. Note NKp44 also has an inhibitory splice isoform (6).

therapeutic candidate. Analysis of blood and tissue samples by the Pastan laboratory identified elevated levels of soluble and surface bound FCRL5 in multiple myeloma, CLL, and mantle cell lymphoma patient samples (33). Studies targeting FCRL5 in myeloma have been conducted by investigators at Genentech (38-40). Two approaches have been pursued including a mAb drug conjugate and a $\mathrm{T}$ cell-dependent bispecific mAb. Preclinical xenograft models employing multiple myeloma samples indicated efficacy for a humanized IgG1 isotype FCRL5 mAb conjugated to monomethyl auristatin E (MMAE) (38). This microtubule inhibitor becomes active when surface receptors bound by the mAb-conjugate are internalized in target cells. A Phase 1 study of this anti-FCRL5-MMAE drug compound (DFRF4539A) in relapsed and refractory multiple myeloma patients $(n=39)$ showed tolerability as a single agent, but demonstrated limited activity and may not be a successful strategy for myeloma (39). The authors speculated that the low response rates in this study could be due to the unknown threshold for Ab-dependent cytotoxicity activity, shedding of the FCRL5 target, limited internalization, and a less effective role of MMAE in cells with a low proliferative index. However, preclinical studies with a bispecific FCRL5/CD3 mAb has shown encouraging activity against patient myeloma cells, can deplete B cells and bone marrow plasma cells in cynomolgus monkeys, and exhibits enhanced activity when combined with PD-L1 blockade (40). These studies indicate that immunotherapeutic targeting of FCRL5 and other FCRL family members expressed by B cells may have utility in a variety of lymphoproliferative disorders.

\section{HUMAN FCRL6 IS AN IMMUNOREGULATORY PROTEIN RESTRICTED TO CYTOTOXIC T AND NK CELLS}

Notably, the first member of the FCRL family identified was a rat FCRL6 ortholog, termed gp42, that was discovered in a search for markers of lymphokine activated killer (LAK) cells (41). Following the discovery of human FCRL1-5, we and others identified human and mouse FCRL6/Fcrl6 counterparts, both of which encode type I TM glycoproteins (42-44). However, the structure and distribution of these FCRL6 molecules among lymphocytes has marked interspecies differences (43). Recent studies with receptor-specific mAbs identified the expression of mFCRL6, which has two Ig like extracellular domains and a short cytoplasmic tail lacking a consensus ITIM or ITAM, by subsets of progenitor B cells in the fetal liver and bone marrow (45). An analysis of pro B cell subsets purified according to the presence or absence of FCRL6 expression, revealed that FCRL6 ${ }^{+}$progenitors have a distinct transcript signature, constrained diversity of their IGHV repertoires, and hydrophobic and charged CDRH3 characteristics akin to innate-like B-1 cells that produce natural Abs (45). However, the regulatory role of mFCRL6 among these pro B cells is not yet defined. Despite syntenic genomic positions, the disparate structure and expression pattern of this family member presents some barriers for in vivo translational understanding of its human relative. In contrast, human FCRL6, which has three extracellular Ig-like domains, an uncharged TM 
region, and a cytoplasmic tail featuring a consensus ITIM, is restricted to cytotoxic T and NK cells $(44,46)$.

The development of receptor-specific mAbs facilitated examination of its ontogeny and distribution in human tissues. FCRL6 is present on mature $\mathrm{NK}$ and $\mathrm{T}$ lymphocytes from adult spleen and blood, but not by these cells from primary developmental sites such as the fetal liver, bone marrow, or thymus (45). Inflammatory tonsillar tissue also lacks significant numbers of FCRL6 ${ }^{+}$cells. Within the blood, FCRL6 marks more terminally differentiated cytotoxic $\mathrm{CD} 16^{+} \mathrm{CD} 56^{\mathrm{dim}} \mathrm{NK}$ cells, a finding that correlates with cytoplasmic perforin and expression of the keratin sulfate-related lactosamine carbohydrate epitope, PEN5 (47). The possibility that FCRL6 expression increases as a function of ontogeny was also confirmed by comparing CD16 ${ }^{+}$ NK cells isolated from cord and adult blood samples. FCRL6 is expressed at significantly higher levels among circulating adult $\mathrm{CD} 6^{+}$cells suggesting that it emerges later in ontogeny than CD16 and segregates NK cells that are more mature (45). Within the $\mathrm{T}$ cell compartment, FCRL6 is present on innate-like $\gamma \delta \mathrm{T}$ cells, but is not biased among $\mathrm{V} \delta 1$ or $\mathrm{V} \delta 2$ subsets. However, its expression by $\gamma \delta \mathrm{T}$ cells similarly correlates with perforin and is relatively more abundant on $\mathrm{CD} 16^{\text {hi }} \mathrm{V} \delta 2$ cells that have greater cytotoxic propensity (48). Among $\mathrm{CD}^{+} \mathrm{T}$ cells, FCRL6 is primarily restricted to perforin-expressing effector $\left(\mathrm{CD}_{4} 5 \mathrm{RA}^{+} \mathrm{CCR}^{-}\right.$or $\left.\mathrm{CD}^{-} 8^{-} 2 \mathrm{~B} 4^{+}\right)$and effector memory $\left(\mathrm{CD} 45 \mathrm{RA}^{-} \mathrm{CCR}^{-}\right.$or $\left.\mathrm{CD}^{-} 8^{+} 2 \mathrm{~B} 4^{+}\right)$subpopulations, rather than central memory or naïve cells. Interestingly, a small ( $\sim 2 \%$ ), but consistent population of $\mathrm{FCRL}^{+} \mathrm{CD} 4^{+} \mathrm{T}$ cells that co-express perforin, CD57, and NKG2D, but lacks CCR7 is present in the blood of some donors (46). Such rare $\mathrm{CD}^{+}{ }^{+} \mathrm{T}$ cells possess cytolytic function (49). These data indicate that FCRL6 distinctly marks mature NK and T cell subpopulations with cytotoxic potential.

\section{FCRL6 RECRUITS SHP-2 TO AN ITIM AND IS AN MHCII/HLA-DR LIGAND}

The presence of two tyrosines in the FCRL6 cytoplasmic tail suggests that, like other FCRLs, it harbors regulatory function. One of these tyrosines (Y371) is positioned among amino acids that conform to a consensus ITIM, but the sequence surrounding both tyrosines (Y356, Y371) could represent a noncanonical ITAM. GST pull down assays of Y356F and Y371F mutants performed with Jurkat lysates uncovered recruitment of the SHIP1 inositol phosphatase as well as the GRB2 adapter protein to the Y356 residue and the SHP1/SHP2 tyrosine phosphatases to the Y371 site (50). Immunoprecipitation of FCRL6 from pervanadate treated NK or T cells validated its capacity for $\mathrm{pY}$ and interactions with multiple $\mathrm{pY}$ proteins [unpublished data and (46)], including SHP-2 to the Y371 residue (44). These findings imply an inhibitory role for FCRL6 in cytotoxic lymphocytes. However, an important question for understanding the fundamental biology of FCRL6 is the nature of its extracellular partner(s).

In flow cytometry-based studies, we were unable to detect Ig binding to FCRL6 by surface staining (46). To search for FCRL6 binding partners, we engineered a cell-based GFP reporter system that expressed a chimeric receptor comprised of the FCRL6 ectodomain in frame with the cytoplasmic tail of mouse $\mathrm{CD} 3 \zeta$ (51). In co-culture assays with various cell types, the FCRL6-CD3 $\zeta$ reporter line was activated by antigen presenting cells (APCs) including B lymphocytes and dendritic cells. This work led to identifying MHCII/HLADR as an FCRL6 ligand. Furthermore, interactions between FCRL6 and HLA-DR appeared to differ according to the nature of the $\beta$ chain component of the heterodimer. This observation suggests that binding affinities between FCRL6 and MHCII may differ according to HLA-DR haplotype. Within the context of this finding FCRL6 is not unique. Several other surface immunoreceptors have also been found to bind MHCII (see Figure 1). Intriguingly, the LAG-3 immunoreceptor, a CD4 relative also expressed by $\mathrm{T}$ cells, is upregulated by exhausted cells in chronic immune conditions including malignancies, and exhibits inhibitory effects through interactions with MHCII/HLA-class II $(52,53)$. Notably, LAG3 has become an attractive immunotherapeutic target and at least three LAG3specific ICI mAbs are in development (54). However, recent work has identified additional non-MHCII ligands for LAG3 (55). Furthermore, a third MHCII receptor expressed by NK cells was recently identified. The natural cytotoxicity receptor NKp44, which has different isoforms as well as expression outside the NK lineage (6), was found to bind subsets of MHCII/HLADP molecules (56). These findings collectively indicate the existence of multiple immunoreceptors that may serve to modulate relationships between cytotoxic lymphocytes and MHCII-expressing cells in different settings [recently reviewed by (57)].

\section{FCRL6-MHCII INTERACTIONS REPRESS EFFECTOR FUNCTIONS BY CYTOTOXIC LYMPHOCYTES}

Efforts to investigate the functional properties of FCRL6 were initially unrevealing. While the genetic regulation of FCRL6 has not yet been explored in detail, modulation experiments showed that the receptor is down-regulated from the NK cell surface when exposed to activating cytokines such as IL-2, IL-12, or IL15 and by $\mathrm{CD}^{+} \mathrm{T}$ cells upon anti-CD3 activation [(44) and our unpublished data]. This analysis suggests that FCRL6 is sensitive to cellular activation. Beyond its induction, re-directed killing assays with FCRL6-expressing NK-92 transfectants or freshly isolated $\mathrm{NK}$ or $\mathrm{CD}^{+} \mathrm{T}$ cells were used to target receptorspecific mAb-coated P815 cells for cytolysis. Work by our group and the Colonna laboratory found no effect for FCRL6 on NK cell degranulation (surface LAMP1 detection), cytoplasmic IFN $\gamma$ production, or the anterograde cytolysis efficiency of ${ }^{51}$ Cr-labeled P815 target cells (44). Furthermore, FCRL6 did not influence activation receptor (CD16)-mediated killing. A potential regulatory role for FCRL6 on cytokine production was also underwhelming. Cultured $\mathrm{CD}^{2} 6^{+} \mathrm{NK}$ cells cross-linked with FCRL6 mAbs demonstrated only slight increases in IFN $\gamma$ and $\mathrm{TNF} \alpha$ production when IL-2 was present, but no impact was 
found for IL-4, IL-5, or IL-10 (44). Furthermore, no differences in cytokine production were observed in similar studies with $\mathrm{CD}^{+} \mathrm{T}$ cells $+/-$ anti-CD3 or IL-2. Thus, FCRL6 does not appear markedly influence cytokine generation by these cytotoxic lymphocytes in vitro.

In recent studies that identified the upregulation of FCRL6 and LAG3 in the microenvironment of $\mathrm{HLA}^{-\mathrm{DR}^{+}}$solid tumors [detailed below and (7)], we revisited FCRL6 function with respect to its $\mathrm{MHCII}$ ligand. The regulation of $\mathrm{NK}$ cell cytotoxicity by MHC class I molecules has been wellcharacterized, and serves as the basis for the "missing-self" hypothesis (58), but evidence also exists that MHC class II expression can protect target cells from NK cell-mediated killing. Early work demonstrated that enforced expression of HLA-DR by K562 cells, a classic human erythroleukemic MHCII-negative target cell line, could inhibit lysis by freshly isolated human NK cells (59). Furthermore, transplantation of HLA-DR ${ }^{+}$K562 cells into NOD/SCID mice provided protection of tumors from elimination by adoptively transferred human blood NK cells (60). We thus generated NK-92 FCRL6 transductants and used them for cytotoxicity assays by employing HLA-DR ${ }^{+} \mathrm{K} 562$ target cells. These experiments demonstrated that HLA-DR expression by K562 cells inhibited the cytotoxicity of FCRL6-expressing NK cells (7). Additional support for this inhibitory axis was found for $\mathrm{CD}^{+} \mathrm{T}$ cell responses. By employing an FCRL6 mAb that disrupts HLA-DR binding to FCRL6-CD3 $\zeta$ reporter cells and in cell staining assays (51), we investigated the effect of FCRL6 blockade during pathogen-specific peptide stimulation in vitro. The addition of FCRL6 or PD-L1 blocking mAbs to healthy donor mononuclear cells co-cultured in MHC class I-restricted peptides from CMV, EBV, and influenza virus epitopes, resulted in enhanced frequencies of IFN $\gamma$ and $\mathrm{TNF} \alpha$ cytokines upon restimulation (7). These studies indicate that FCRL6 is a potentially novel ICI target capable of suppressing effector cell activity following engagement with HLA-class II molecules.

\section{FCRL6 ${ }^{+}$NK AND T LYMPHOCYTES EXPAND IN CHRONIC IMMUNE DISORDERS}

The significance of FCRL6 in immune-related disorders was first shown by Wilson et al. who found significantly expanded FCRL6 $^{+}$effector and effector memory CD8 ${ }^{+} \mathrm{T}$ cell frequencies in HIV-1 infected individuals (44). This expression pattern did not seem to correlate with viral titers or $\mathrm{CD}^{+}$counts. An increase in circulating FCRL6 ${ }^{+} \mathrm{CD} 4^{+}$cells, which are typically rare among healthy individuals, was also detected in $\mathrm{HIV}^{+}$donor samples. Initial evidence for a role in tumor immunology came from studies in CLL. Unlike the other FCRL molecules that are expressed by CLL B cells (34), FCRL6 expression by the $\mathrm{B}$ cell clone was undetectable. Instead, increased frequencies of FCRL6 $^{+}$NK and T lymphocytes were evident in the circulation of CLL patients (46). While blood $\mathrm{CD}^{+} \mathrm{T}$ cells are generally expanded in CLL, $\mathrm{T}$ cells derived from these patients are also known to have abnormal function $(61,62)$. An analysis of CLL donors from our cohort demonstrated that, in addition to a global increase in CD8 T cells, the frequencies of effector and effector memory cell populations were elevated compared to healthy control samples (46). The frequency of FCRL6 ${ }^{+}$cells among these $\mathrm{CD}^{+}$subsets was also greater in CLL patients, as were FCRL6-expressing NK cells and cytotoxic $\mathrm{CD} 4{ }^{+}$cells. These findings suggest that the expansion of FCRL $6^{+}$cytotoxic T and NK cells in different disease states could reflect the influence of chronic immune activation on the terminal differentiation of effector cells and contribute to their dysfunction. Furthermore, the increased numbers of cytotoxic cells marked by FCRL6 could reflect a blunted capacity for clearance of the inciting disease process by taking advantage of its potential inhibitory properties. This could infer a role for cytokines or some other systemic influence on the expansion of FCRL $6^{+}$cells, but the mechanistic basis for this remains undefined.

\section{FCRL6 EXPRESSION IS UPREGULATED IN SOLID TUMORS EXPRESSING HLA CLASS II}

Evidence that an inhibitory receptor restricted to cytotoxic lymphocytes interacts with MHCII/HLA-DR suggests that FCRL6 might have roles in tolerance through its interactions with APCs as well as other non-traditional MHCII-expressing cells including malignancies (see Figure 1). The endogenous expression of MHCII/HLA-DR molecules by tumor cells has been observed in many cancers including $40-50 \%$ of melanoma cases $(63,64)$. Importantly, MHCII expression correlates with favorable clinical responses to anti-PD-1 ICI in melanoma, classical Hodgkin's disease, breast cancer, and ovarian cancer (64-67). In breast cancer, PD-1 inhibition is more efficacious in the triple negative subtype (TNBC) (68), but responses vary by PD-1/PD- L1 expression and TIL frequencies (69). Accordingly, MHCII is expressed by $\sim 30 \%$ of TNBC cases (70) and portends increased therapeutic responses and TIL recruitment $(71,72)$. Despite the clinical favorability of $\mathrm{MHCII}^{+}$status, chronic ICI therapy typically leads to tumor resistance by adaptation and the delivery of immunosuppressive signals through alternative checkpoint pathways (4).

To investigate these evasion mechanisms, in collaboration with Johnson and Balko, we recently performed transcriptome profiling and tissue staining of patients who developed resistance to $\mathrm{PD}-1$ immunotherapy in melanoma, non-small cell lung cancer (NSCLC), and TNBC (18). This study included melanoma and NSCLC samples $(n=58)$ before and after targeted PD-1 ICI. $\mathrm{MHCII}^{+}$tumors, confirmed by dual RNA-in situ and immunohistochemistry analysis, demonstrated an adaptive immune signature including the upregulation of genes encoding CD4, CD8a, and ICI receptors. Chiefly among these was LAG3, which was exclusively expressed by infiltrating $\mathrm{T}$ cells with a bias toward $\mathrm{CD}^{+}$rather than $\mathrm{CD}^{+}$cells. A comparison of melanoma samples derived from patients pre and post anti-PD1 treatment revealed increased frequencies of LAG3 ${ }^{+}$TILs as a function of developing adaptive resistance in paired specimens. High levels of $\mathrm{LAG}^{+}$TILs were also found in $\mathrm{MHCII}^{+}$ TNBC $(n=112)$ and were associated with $\mathrm{CD}^{+}$infiltrates. 


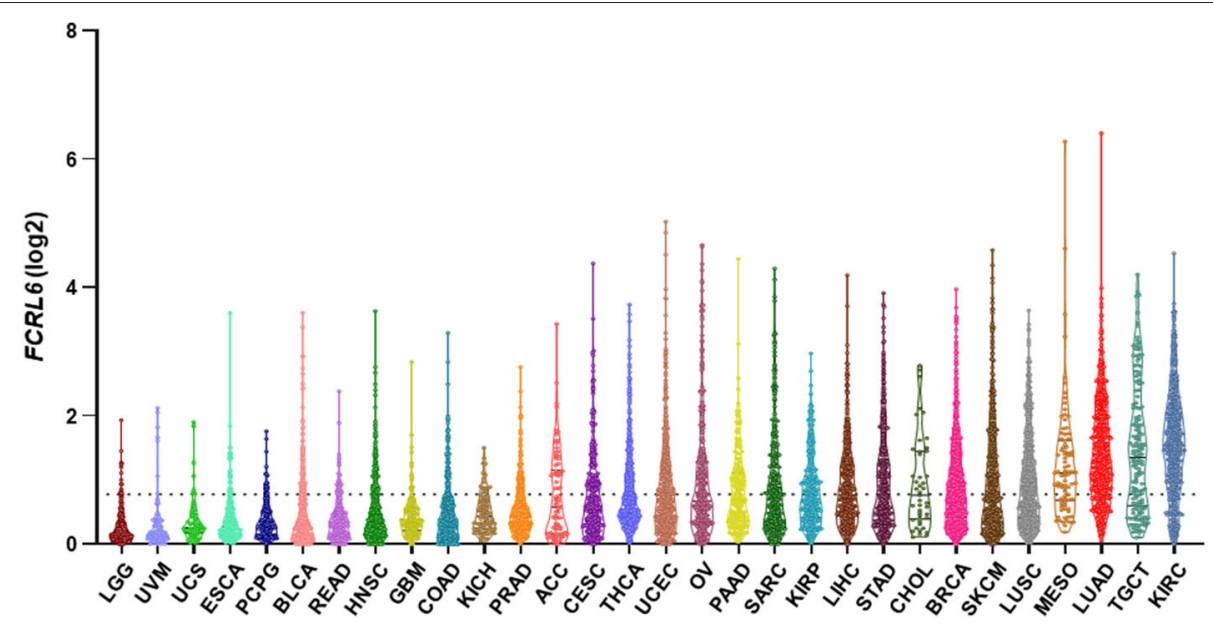

FIGURE 2 | FCRL6 expression among various cancers. A violin plot demonstrating the expression (log2) of FCRL6 (ENSG00000181036) in non-hematopoietic cancers $(n=30)$ from The Cancer Genome Atlas (TCGA) (73). LGG, lower grade glioma ( $n=529)$; UVM, uveal melanoma $(n=80)$; UCS, uterine carcinosarcoma ( $n=56)$; ESCA, esophageal carcinoma ( $n=173)$; PCPG, pheochromocytoma and paraganglioma $(n=186)$; BLCA, bladder carcinoma ( $n=427)$; READ, rectum adenocarcinoma ( $n=177)$; HNSC, head and neck squamous cell carcinoma $(n=546)$; GBM, glioblastoma $(n=174)$; COAD, colon adenocarcinoma $(n=499)$; $\mathrm{KICH}$, kidney chromophobe $(n=89)$; PRAD, prostate adenocarcinoma $(n=548)$; ACC, adrenocortical carcinoma $(n=79)$; CESC, cervical squamous carcinoma $(n=309)$; THCA, thyroid carcinoma $(n=568)$; UCEC, uterine corpus endometrial carcinoma $(n=579)$; OV, ovarian serous cystadenocarcinoma $(n=379)$; PAAD, pancreatic adenocarcinoma $(n=182)$; SARC, sarcoma $(n=265)$; KIRP, kidney renal papillary cell carcinoma $(n=320)$; LIHC, liver hepatocellular carcinoma $(n=424)$; STAD, stomach adenocarcinoma ( $n=407)$; CHOL, cholangiocarcinoma $(n=45)$; BRCA, breast carcinoma $(n=1,205)$; SKCM, skin cutaneous melanoma $(n=472)$; LUSC, lung squamous cell carcinoma $(n=551)$; MESO, mesothelioma ( $n=86)$; LUAD, lung adenocarcinoma $(n=573)$; TGCT, testicular germ cell tumor $(n=156)$; and KIRC, kidney renal clear cell carcinoma $(n=599)$. The median and quartiles are demarcated (black lines) for samples in the plot of each cancer subtype. RPKM transcript data were downloaded from the R2: Genomics Analysis and Visualization Platform (http://r2.amc.nl), plotted using Prism software, and ordered by median values of expression. The dotted black line indicates the mean expression value ( $F C R L 6 \log 2=0.78)$ of the 30 cancer subtypes. Note that THCA and cancers to the right on the plot exceed the mean.

Given the known interaction between LAG3 and MHCII (52, 53), these findings implied that tumors may exploit MHCII expression to blunt eradication by TILs. This hypothesis was further supported by studies in an in vivo MMTV-neu breast cancer mouse model. Enforced MHCII expression generally promoted tumor rejection and CD4 recruitment, but in mice that formed refractory tumors, there was evidence of adaptive resistance including the upregulation of chemokines that foster $\mathrm{T}$ cell recruitment as well as the $P d c d 1$ (Pd-1) and Lag3 inhibitory receptor genes. Importantly, anti-tumor immunity was enhanced by treatment with a combination of anti-PD-1 and LAG3 ICI.

With clinical and mechanistic evidence that $\mathrm{MHCII}^{+}$tumors may actively suppress effector cell cytotoxicity, we turned to the possibility that FCRL6 may operate similarly in this process. As detailed above, FCRL6 suppressed NK cell cytotoxicity of HLADR expressing target cells and enhanced effector T cell cytokine production following Ab-mediated blockade. Like LAG3, FCRL6 was more highly expressed by $\mathrm{MHCII}^{+}$melanomas and NSCLCs. While a similar trend was evident for FCRL3, it did not reach significance. A linear relationship was also evident for LAG3 and FCRL6 with the degree of HLA-DR ${ }^{+}$tumor cells. Similarly, both FCRL6 transcript and protein expression was elevated in melanoma samples from patients who experienced relapse after progression on anti-PD-1 ICI therapy. Consequently, FCRL6 ${ }^{+}$ infiltrates also correlated with LAG3 and HLA-DR status in TNBC. Staining of TNBC specimens showed that TIL coexpression of FCRL6 and LAG3 was strongly correlated with elevated tumor-specific HLA-DR expression. Finally, in these breast tumors, an inverse correlation was found for FCRL6 and LAG3 reactivity with the fraction of granzyme $\mathrm{B}^{+}$cytotoxic $\mathrm{CD}^{+}$cells present. This disclosed a potential suppressive role for these ICI receptors in the tumor microenvironment. These findings collectively implicate a novel inhibitory role for FCRL6 in cell-mediated responses to $\mathrm{MHCII}^{+}$tumors and its potential as a new ICI target that influences adaptive resistance mechanisms to anti-PD-1 therapy.

\section{FCRL6 UPREGULATION BY MALIGNANCIES HAS PROGNOSTIC SIGNIFICANCE}

Given its discrete expression by cytotoxic $\mathrm{T}$ and $\mathrm{NK}$ lymphocytes and newfound role in tumor immunity, we explored the possibility that detection of FCRL6 in the tumor microenvironment could have prognostic clinical significance. To pursue this hypothesis, we analyzed FCRL6 transcript expression from RNA-sequencing data performed on 30 nonhematopoietic cancer types (10,683 samples) from TCGA (73) (Figure 2). FCRL6 expression ( $\log 2$ ) was heterogeneous among these cancer types but, in accord with our recent findings (7), lung adenocarcinomas (LUAD), cutaneous melanomas (SKCM), and breast carcinomas (BRCA) were among the tumors with higher median expression levels. We next assessed survival in these cancer types according to FCRL6 expression. By 
Cutaneous Melanoma (SKCM)

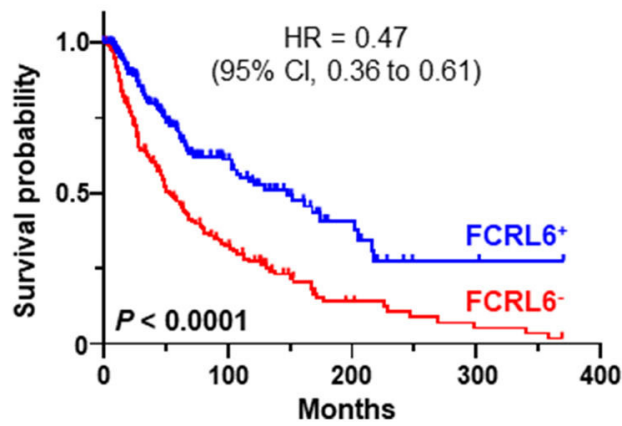

Lung Adenocarcinoma (LUAD)

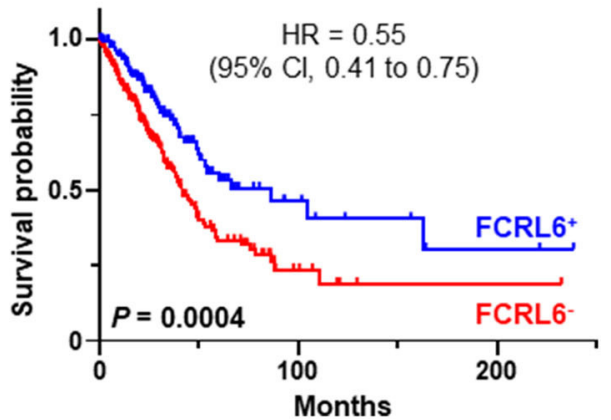

FIGURE 3 | FCRL6 overexpression predicts favorable overall survival (OS) in cutaneous melanoma and lung adenocarcinoma. Kaplan-Meier plots demonstrating the relationship between FCRL6 gene expression and patient clinical outcomes by OS. TCGA (reads per kilobase million-RPKM) transcript data for SKCM ( $n=458$ ) and LUAD ( $n=497$ ) were downloaded from the publicly available cBioPortal (https://www.cbioportal.org/) database (74) for analysis with the R2: Genomics Analysis and Visualization Platform (http://r2.amc.nl). Optimal threshold cut-off values for determining high or low FCRL6 expression as a continuous variable were compared using Cox Regression analysis and the R2 Genomics platform. Comparisons of OS curves and P-values were made using the Log-rank test. Hazard ratio (HR) and 95\% confidence interval $(\mathrm{Cl})$ for comparisons between the groups are indicated. Kaplan-Meier plots were generated using Prism software.
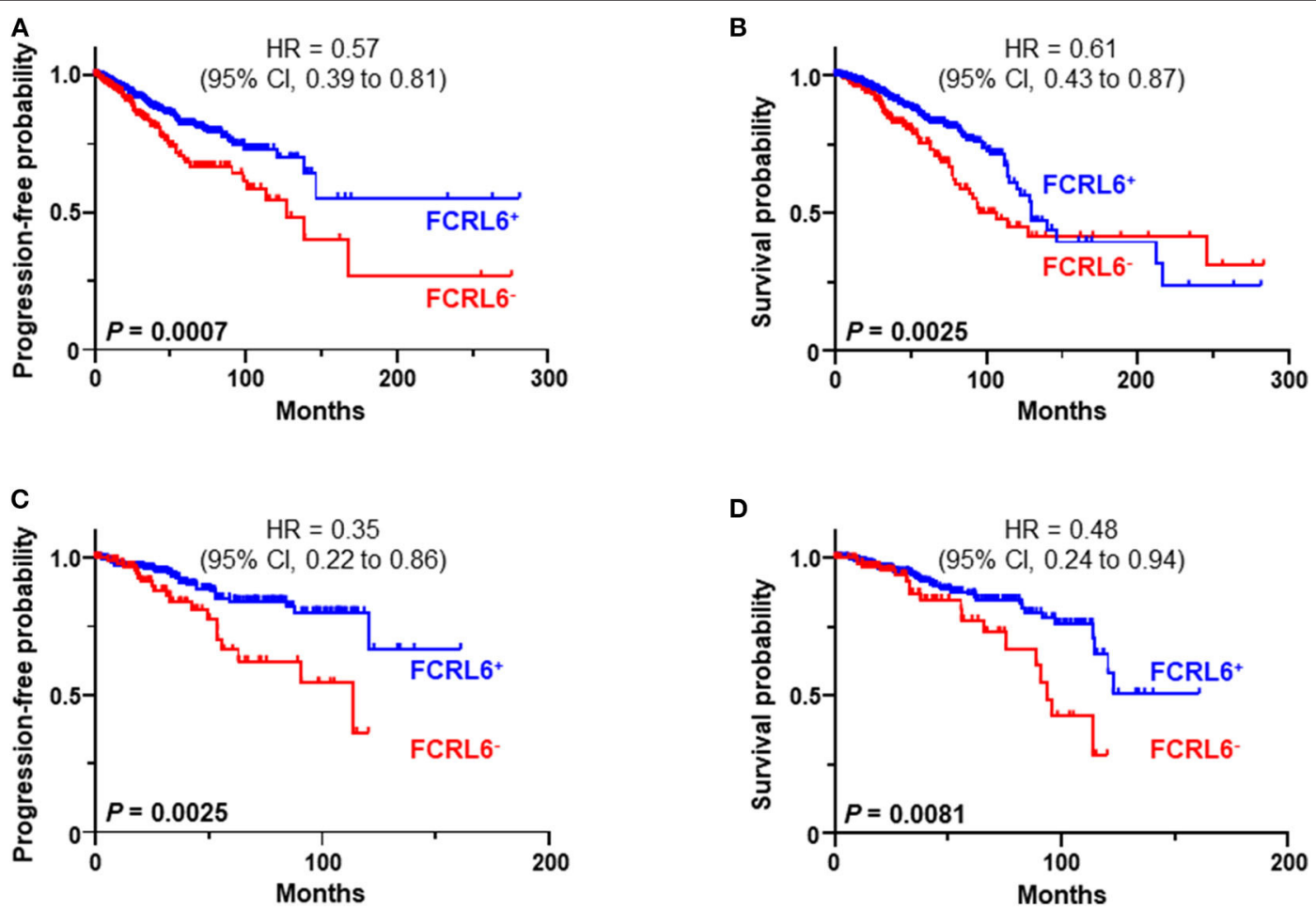

FIGURE 4 | FCRL6 overexpression predicts favorable progression free (PFS) and overall survival (OS) in breast carcinoma. Kaplan-Meier plots demonstrating the relationship between FCRL6 gene expression and patient clinical outcomes by PFS and OS for $\mathbf{( A , B )}$ all breast carcinomas $(\mathrm{BRCA}, n=1,067)$ and $\mathbf{( C , D )}$ Her2 negative samples $(n=550)$. TCGA (reads per kilobase million-RPKM) transcript data for BRCA were downloaded from the publically available cBioPortal (https:// www.cbioportal.org/) database (74) for analysis with the R2: Genomics Analysis and Visualization Platform (http://r2.amc.nl). Optimal threshold cut-off values for determining high or low FCRL6 expression as a continuous variable were compared using Cox Regression analysis and the R2 Genomics platform. Comparisons of PFS and OS curves and P-values were made using the Log-rank test. HR and 95\% Cl for comparisons between the groups are indicated. Kaplan-Meier plots were generated using Prism software.

employing Cox Regression analysis along with the R2: Genomics Analysis and Visualization Platform (http://r2.amc.nl), we defined optimized cut-off values to segregate samples according to FCRL6 expression. Kaplan-Meier plots demonstrated that higher FCRL6 expression predicted increased overall survival (OS) in SKMM $(n=458)$ and LUAD $(n=497)$ TCGA samples 


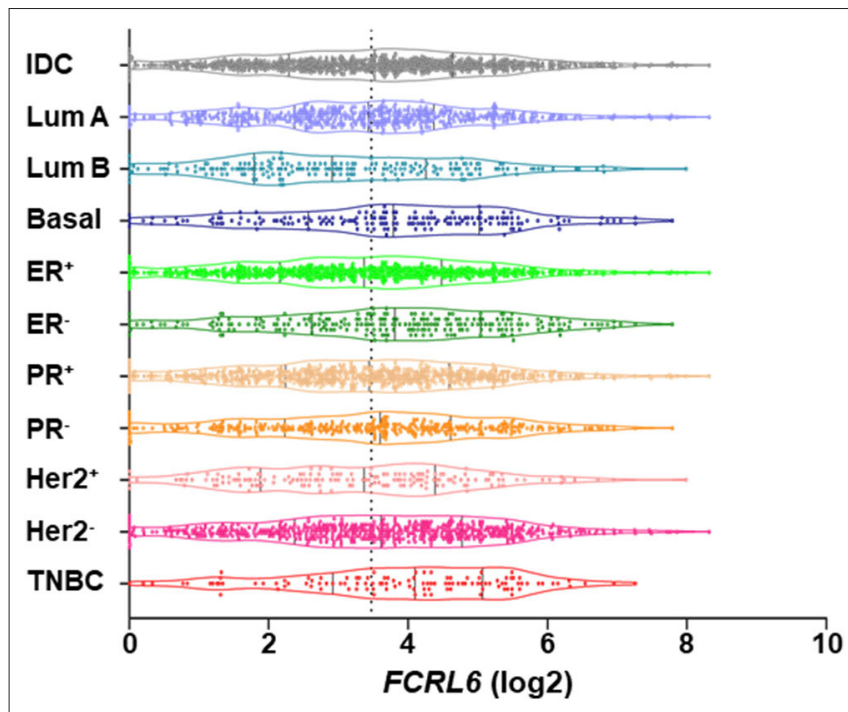

FIGURE 5 | Among breast cancer subtypes FCRL6 transcript expression is highest in TNBC. A violin plot demonstrating the mean expression (log2) of FCRL6 (ENSG00000181036) among TCGA BRCA tumor subtypes downloaded from the publicly available cBioPortal (https://www.cbioportal. org/) database (74). Intraductal carcinoma (IDC, $n=976)$, Luminal A (Lum A, $n=499)$, Luminal B (Lum B, $n=197)$, Basal $(n=171)$, estrogen receptor positive (ER $\left.{ }^{+}, n=795\right)$, ER negative (ER $\left.{ }^{-}, n=237\right)$, progesterone receptor positive $\left(\mathrm{PR}^{+}, n=687\right)$, $\mathrm{PR}$ negative ( $\left.\mathrm{PR}^{-}, n=342\right)$, Her2 receptor positive (Her2 ${ }^{+}, n=160$ ) Her2 receptor negative (Her2 ${ }^{-}, n=557$ ), and triple negative breast cancer (TNBC, $n=115$ ). The median and quartiles are demarcated (black lines) for samples in the plot of each subtype. Mean $(x)$ FCRL6 expression \pm SEM: TNBC (3.905 \pm 0.1455$),$ ER $^{-}$(3.76 \pm 0.1104$)$, Basa (3.733 \pm 0.1296$),$ Her2 $^{-}$(3.543 \pm 0.07162$)$, IDC (3.466 \pm 0.05328$), \mathrm{PR}^{-}$ (3.449 \pm 0.09192$\left.), \mathrm{PR}^{+} 3.396 \pm 0.06334\right)$, Lum A (3.384 \pm 0.07137$), \mathrm{ER}^{+}$ (3.316 \pm 0.05859$),$ Her2 $^{+}$(3.263 \pm 0.1262$)$, and Lum B (3.022 \pm 0.1196$)$. Note the dotted black line indicates the mean value (FCRL6 log2 $=3.47$ ) of the 11 breast cancer subtypes.

(Figure 3). In SKMM, median OS was 2.7-fold higher for patients with elevated FCRL6 expression. Patients with FCRL6-positive tumors had a median OS of 148.2 months vs. 54.4 months for samples with low FCRL6 transcripts $(\mathrm{HR}=0.47, \mathrm{CI}=0.36-0.61$, $P<0.0001)$. In LUAD, elevated FCRL6 predicted a 2.1 -fold higher median OS. FCRL6 ${ }^{+}$tumors exhibited a median OS of 86.0 months vs. 41.7 months for FCRL6 ${ }^{-}$samples $(\mathrm{HR}=0.55$, CI $=0.41-0.75, P=0.0004)$. Consistent with the known responsiveness of these tumors to ICI therapy and the TIL concentrations in the tumor microenvironment (75-82), these findings indicate that elevated FCRL6 expression confers a generally favorable prognosis for the OS of patients with these tumors.

We next investigated FCRL6 expression among BRCA ( $n=1,067)$ TCGA samples (Figure 4). FCRL6 was able to predict progression free survival (PFS) among all BRCA samples with elevated transcript expression again correlating with a favorable outcome (Figure 4A). For FCRL6-high cases the median PFS was not reached for this TCGA BRCA cohort, while the median PFS for FCRL6-low cases was 113.8 months $(\mathrm{HR}=0.44$, $\mathrm{CI}=0.22-0.86, P=0.0025)$. Interestingly, analysis of $\mathrm{OS}$ indicated an advantage for patients with tumors possessing high FCRL6 transcripts (Figure 4B). Median OS was 129.7 months for FCRL6-high cases and 107.2 months for patient samples with FCRL6-low expression ( $\mathrm{HR}=0.61, \mathrm{CI}=0.43-0.97, P=0.0025)$. This benefit across this entire series of TCGA BRCA tumors appeared evident for up to 12 years after diagnosis, but for patients with FCRL6-high samples that lived beyond this time period ( $n=10 / 19$ ), this factor became detrimental. Notably, this is a minority of patients from a heterogeneous cohort of samples and mortality at later time points beyond diagnosis and treatment could be multifactorial for this group. With regard to the disease status of these 10 individuals, six were tumor-free at death, two died with positive tumor status, and data was not available for two cases. We additionally assessed TCGA BRCA samples from patients with Her2 negative status $(n=550)$ (Figures 4C,D). Elevated FCRL6 expression in patients with Her2 negative tumors was prognostically advantageous for both PFS and OS. Median PFS for patients with FCRL6 high Her2 negative tumors was not reached while for low expressors it was 113.8 months $(\mathrm{HR}=0.44, \mathrm{CI}=0.22-0.86$, $P=0.0025)$. Median OS for FCRL6-high Her2 negative BRCA tumors was also not reached and for FCRL6-low expression was 93.8 months ( $\mathrm{HR}=0.48, \mathrm{CI}=0.25-0.94, P=0.0081)$. Elevated FCRL6 expression also portended significantly higher PFS and OS in patients with intraductal breast carcinoma $(n=765)$ and estrogen positive $(n=782)$ tumor status (data not shown). To better understand the distribution of FCRL6 ${ }^{+}$ TILs within the context of BRCA heterogeneity, we analyzed the mean expression levels of FCRL6 among 11 different BRCA subtypes. The highest FCRL6 transcripts were found in TNBC, followed by $\mathrm{ER}^{-}>$Basal $>$Her2 ${ }^{-}$tumor samples (Figure 5). These findings parallel the known elevated frequency of cytotoxic lymphocytes and NK cell TILs in TNBC that are associated with an improved prognosis as well as the sensitivity of these tumors to ICI and neoadjuvant chemotherapy (69, 72, 83-85). While analysis of FCRL6 protein expression by primary samples would be helpful for validation, given its restricted expression by cytotoxic lymphocytes, these findings at the transcript level support the potential utility of FCRL6 as a prognostic marker and ICI target.

\section{CONCLUDING REMARKS}

In summary, members of the FCRL family are preferentially expressed by $\mathrm{B}$ cells and generally exert inhibitory tyrosine-based regulation on BCR signaling. Given their expression by $\mathrm{B}$ cells there is a growing appreciation of their roles in lymphoproliferative disorders and potential as immunotherapeutic targets. In contrast to FCRL1-5, FCRL6 has a distinct expression pattern outside the B lineage among cytotoxic $\mathrm{T}$ and NK lymphocytes. Furthermore, its elevated expression in the tumor microenvironment, including NSCLC, melanoma, and breast cancer, significantly correlates with improved PFS and OS. However, its ITIM-based repressive function in these cells becomes operative upon engagement with its partner MHCII/HLA-DR. This newfound axis has growing 
significance in tumor immunology as endogenous HLA class II expression by cancer cells has been found to correlate with increased TIL numbers, responsiveness to anti PD-1 directed ICI, and a more favorable prognosis. However, some tumors that develop resistance to ICI appear to upregulate HLA class II to blunt recognition by cytotoxic cells expressing FCRL6 as well as other MHCII-binding molecules (e.g., LAG3 and NKp44). Thus, FCRL6 may serve as a novel ICI target. Future studies that model its in vivo regulation are required to investigate this possibility, but are hampered by the interspecies diversity of this FCRL representative in mice and humans. Additionally, the distinct MHCII allotypes that FCRL6 interacts with, and how these relationships impact cytotoxic cells during homeostasis in tolerance with APCs vs. disease states, are important topics for future study.

\section{REFERENCES}

1. Balar AV, Weber JS. PD-1 and PD-L1 antibodies in cancer: current status and future directions. Cancer Immunol Immunother. (2017) 66:55164. doi: 10.1007/s00262-017-1954-6

2. Postow MA, Callahan MK, Wolchok JD. Immune checkpoint blockade in cancer therapy. J Clin Oncol. (2015) 33:197482. doi: 10.1200/JCO.2014.59.4358

3. Haslam A, Prasad V. Estimation of the percentage of US patients with cancer who are eligible for and respond to checkpoint inhibitor immunotherapy drugs. JAMA Netw Open. (2019) 2:e192535. doi: 10.1001/jamanetworkopen.2019.2535

4. Koyama S, Akbay EA, Li YY, Herter-Sprie GS, Buczkowski KA, Richards WG, et al. Adaptive resistance to therapeutic PD-1 blockade is associated with upregulation of alternative immune checkpoints. Nat Commun. (2016) 7:10501. doi: 10.1038/ncomms10501

5. Wang DY, Eroglu Z, Ozgun A, Leger PD, Zhao S, Ye F, et al. Clinical features of acquired resistance to anti-pd-1 therapy in advanced melanoma. Cancer Immunol Res. (2017) 5:357-62. doi: 10.1158/2326-6066.CIR-16-0287

6. Cantoni C, Bottino C, Vitale M, Pessino A, Augugliaro R, Malaspina A, et al. NKp44, a triggering receptor involved in tumor cell lysis by activated human natural killer cells, is a novel member of the immunoglobulin superfamily. $J$ Exp Med. (1999) 189:787-96. doi: 10.1084/jem.189.5.787

7. Johnson DB, Nixon MJ, Wang Y, Wang DY, Castellanos E, Estrada MV, et al. Tumor-specific MHC-II expression drives a unique pattern of resistance to immunotherapy via LAG-3/FCRL6 engagement. JCI insight. (2018) 3:e120360. doi: 10.1172/jci.insight. 120360

8. Davis RS. Fc receptor-like molecules. Annu Rev Immunol. (2007) 25:52560. doi: 10.1146/annurev.immunol.25.022106.141541

9. Li FJ, Won WJ, Becker EJ Jr, Easlick JL, Tabengwa EM, Li R, et al. Emerging roles for the FCRL family members in lymphocyte biology and disease. Curr Top Microbiol Immunol. (2014) 382:29-50. doi: 10.1007/978-3-319-07911-0_2

10. Bulian P, Shanafelt TD, Fegan C, Zucchetto A, Cro L, Nuckel H, et al. CD49d is the strongest flow cytometry-based predictor of overall survival in chronic lymphocytic leukemia. J Clin Oncol. (2014) 32:897904. doi: 10.1200/JCO.2013.50.8515

11. Polson AG, Zheng B, Elkins K, Chang W, Du C, Dowd P, et al. Expression pattern of the human FcRH/IRTA receptors in normal tissue and in B-chronic lymphocytic leukemia. Int Immunol. (2006) 18:136373. doi: 10.1093/intimm/dxl069

12. Nagata S, Ise T, Pastan I. Fc receptor-like 3 protein expressed on IL2 nonresponsive subset of human regulatory T cells. J Immunol. (2009) 182:7518-26. doi: 10.4049/jimmunol.0802230

13. Swainson LA, Mold JE, Bajpai UD, McCune JM. Expression of the autoimmune susceptibility gene FcRL3 on human regulatory $\mathrm{T}$ cells is associated with dysfunction and high levels of programmed cell death-1. $J$ Immunol. (2010) 184:3639-47. doi: 10.4049/jimmunol.0903943

\section{AUTHOR CONTRIBUTIONS}

RSD wrote and edited the manuscript.

\section{FUNDING}

This work was supported in part by the V Foundation for Cancer Research, Breast Cancer Research Foundation of Alabama, and the UAB Cancer Immunobiology Program.

\section{ACKNOWLEDGMENTS}

The author thanks Dr. Yufeng Li for statistical advice and Peter D. Burrows and Robert S. Welner for critically reading the manuscript.

14. Leu CM, Davis RS, Gartland LA, Fine WD, Cooper MD. FcRH1: an activation coreceptor on human B cells. Blood. (2005) 105:11216. doi: 10.1182/blood-2004-06-2344

15. Zhao X, Xie H, Zhao M, Ahsan A, Li X, Wang F, et al. Fc receptor-like 1 intrinsically recruits c-Abl to enhance B cell activation and function. Sci Adv. (2019) 5:eaaw0315. doi: 10.1126/sciadv.aaw0315

16. Davis RS, Stephan RP, Chen CC, Dennis G Jr, Cooper MD. Differential B cell expression of mouse Fc receptor homologs. Int Immunol. (2004) 16:134353. doi: 10.1093/intimm/dxh137

17. Ehrhardt GR, Davis RS, Hsu JT, Leu CM, Ehrhardt A, Cooper MD. The inhibitory potential of Fc receptor homolog 4 on memory B cells. Proc Natl Acad Sci USA. (2003) 100:13489-94. doi: 10.1073/pnas.1935944100

18. Haga CL, Ehrhardt GR, Boohaker RJ, Davis RS, Cooper MD. Fc receptor-like 5 inhibits B cell activation via SHP-1 tyrosine phosphatase recruitment. Proc Natl Acad Sci USA. (2007) 104:9770-5. doi: 10.1073/pnas.0703354104

19. Jackson TA, Haga CL, Ehrhardt GR, Davis RS, Cooper MD. FcR-like 2 Inhibition of B cell receptor-mediated activation of B cells. J Immunol. (2010) 185:7405-12. doi: 10.4049/jimmunol.1002305

20. Kochi Y, Myouzen K, Yamada R, Suzuki A, Kurosaki T, Nakamura $\mathrm{Y}$, et al. FCRL3, an autoimmune susceptibility gene, has inhibitory potential on B-cell receptor-mediated signaling. J Immunol. (2009) 183:550210. doi: 10.4049/jimmunol.0901982

21. Zhu Z, Li R, Li H, Zhou T, Davis RS. FCRL5 exerts binary and compartmentspecific influence on innate-like B-cell receptor signaling. Proc Natl Acad Sci USA. (2013) 110:E1282-90. doi: 10.1073/pnas.1215156110

22. Won WJ, Foote JB, Odom MR, Pan J, Kearney JF, Davis RS. Fc receptor homolog 3 is a novel immunoregulatory marker of marginal zone and B1 B cells. J Immunol. (2006) 177:6815-23. doi: 10.4049/jimmunol.177.10.6815

23. Nimmerjahn F, Ravetch JV. Fcgamma receptors: old friends and new family members. Immunity. (2006) 24:19-28. doi: 10.1016/j.immuni.2005.11.010

24. Sohn HW, Krueger PD, Davis RS, Pierce SK. FcRL4 acts as an adaptive to innate molecular switch dampening BCR signaling and enhancing TLR signaling. Blood. (2011) 118:6332-41. doi: 10.1182/blood-2011-05-353102

25. Li FJ, Schreeder DM, Li R, Wu J, Davis RS. FCRL3 promotes TLR9-induced B-cell activation and suppresses plasma cell differentiation. Eur J Immunol. (2013) 43:2980-92. doi: 10.1002/eji.201243068

26. Liu Y, Bezverbnaya K, Zhao T, Parsons MJ, Shi M, Treanor $\mathrm{B}$, et al. Involvement of the HCK and FGR src-family kinases in FCRL4-mediated immune regulation. J Immunol. (2015) 194:5851-60. doi: 10.4049/jimmunol.1401533

27. Wilson TJ, Fuchs A, Colonna M. Cutting edge: human FcRL4 and FcRL5 are receptors for IgA and IgG. J Immunol. (2012) 188:47415. doi: 10.4049/jimmunol.1102651

28. Hatzivassiliou G, Miller I, Takizawa J, Palanisamy N, Rao PH, Iida S, et al. IRTA1 and IRTA2, novel immunoglobulin superfamily receptors expressed in $\mathrm{B}$ cells and involved in chromosome 1q21 abnormalities in B cell malignancy. Immunity. (2001) 14:277-89. doi: 10.1016/S1074-7613(01)00109-1 
29. Franco A, Damdinsuren B, Ise T, Dement-Brown J, Li H, Nagata $\mathrm{S}$, et al. Human $\mathrm{Fc}$ receptor-like 5 binds intact IgG via mechanisms distinct from those of Fc receptors. J Immunol. (2013) 190:573946. doi: 10.4049/jimmunol.1202860

30. Agarwal S, Kraus Z, Dement-Brown J, Alabi O, Starost K, Tolnay M. Human Fc receptor-like 3 inhibits regulatory $\mathrm{T}$ cell function and binds secretory IgA. Cell Rep. (2020) 30:1292-9.e3. doi: 10.1016/j.celrep.2019.12.099

31. Miller I, Hatzivassiliou G, Cattoretti G, Mendelsohn C, Dalla-Favera R. IRTAs: a new family of immunoglobulinlike receptors differentially expressed in B cells. Blood. (2002) 99:2662-9. doi: 10.1182/blood.V99.8.2662

32. Alizadeh AA, Eisen MB, Davis RE, Ma C, Lossos IS, Rosenwald A, et al. Distinct types of diffuse large B-cell lymphoma identified by gene expression profiling. Nature. (2000) 403:503-11. doi: 10.1038/35000501

33. Ise T, Nagata S, Kreitman RJ, Wilson WH, Wayne AS, Stetler-Stevenson M, et al. Elevation of soluble CD307 (IRTA2/FcRH5) protein in the blood and expression on malignant cells of patients with multiple myeloma, chronic lymphocytic leukemia, and mantle cell lymphoma. Leukemia. (2007) 21:16974. doi: 10.1038/sj.leu.2404445

34. Li FJ, Ding S, Pan J, Shakhmatov MA, Kashentseva E, Wu J, et al. FCRL2 expression predicts IGHV mutation status and clinical progression in chronic lymphocytic leukemia. Blood. (2008) 112:179-87. doi: 10.1182/blood-2008-01-131359

35. Shea LK, Honjo K, Redden DT, Tabengwa E, Li R, Li FJ, et al. Fc receptor-like 2 (FCRL2) is a novel marker of low-risk CLL and refines prognostication based on IGHV mutation status. Blood Cancer J. (2019) 9:47. doi: 10.1038/s41408-019-0207-7

36. Damle RN, Wasil T, Fais F, Ghiotto F, Valetto A, Allen SL, et al. Ig $\mathrm{V}$ gene mutation status and $\mathrm{CD} 38$ expression as novel prognostic indicators in chronic lymphocytic leukemia. Blood. (1999) 94:18407. doi: 10.1182/blood.V94.6.1840

37. Hamblin TJ, Orchard JA, Ibbotson RE, Davis Z, Thomas PW, Stevenson FK, et al. CD38 expression and immunoglobulin variable region mutations are independent prognostic variables in chronic lymphocytic leukemia, but CD38 expression may vary during the course of the disease. Blood. (2002) 99:1023-9. doi: 10.1182/blood.V99.3.1023

38. Elkins K, Zheng B, Go M, Slaga D, Du C, Scales SJ, et al. FcRL5 as a target of antibody-drug conjugates for the treatment of multiple myeloma. Mol Cancer Ther. (2012) 11:2222-32. doi: 10.1158/1535-7163.MCT-12-0087

39. Stewart AK, Krishnan AY, Singhal S, Boccia RV, Patel MR, Niesvizky R, et al. Phase I study of the anti-FcRH5 antibody-drug conjugate DFRF4539A in relapsed or refractory multiple myeloma. Blood Cancer J. (2019) 9:17. doi: 10.1038/s41408-019-0178-8

40. Li J, Stagg NJ, Johnston J, Harris MJ, Menzies SA, DiCara D, et al. Membraneproximal epitope facilitates efficient $\mathrm{T}$ cell synapse formation by antiFcRH5/CD3 and is a requirement for myeloma cell killing. Cancer Cell. (2017) 31:383-95. doi: 10.1016/j.ccell.2017.02.001

41. Imboden JB, Eriksson EC, McCutcheon M, Reynolds CW, Seaman WE. Identification and characterization of a cell-surface molecule that is selectively induced on rat lymphokine-activated killer cells. J Immunol. (1989) 143:31003.

42. Guselnikov SV, Ershova SA, Mechetina LV, Najakshin AM, Volkova OY, Alabyev BY, et al. A family of highly diverse human and mouse genes structurally links leukocyte FcR, gp42 and PECAM-1. Immunogenetics. (2002) 54:87-95. doi: 10.1007/s00251-002-0436-x

43. Davis RS, Dennis G Jr., Odom MR, Gibson AW, Kimberly RP, et al. Fc receptor homologs: newest members of a remarkably diverse Fc receptor gene family. Immunol Rev. (2002) 190:123-36. doi: 10.1034/j.1600-065X.2002.19009.x

44. Wilson TJ, Presti RM, Tassi I, Overton ET, Cella M, Colonna M. FcRL6, a new ITIM-bearing receptor on cytolytic cells, is broadly expressed by lymphocytes following HIV-1 infection. Blood. (2007) 109:378693. doi: 10.1182/blood-2006-06-030023

45. Honjo K, Won WJ, King RG, Ianov L, Crossman DK, Easlick JL, et al. Fc Receptor-Like 6 (FCRL6) discloses progenitor B cell heterogeneity that correlates with pre-BCR dependent and independent pathways of natural antibody selection. Front Immunol. (2020) 11:82. doi: 10.3389/fimmu.2020.00082

46. Schreeder DM, Pan J, Li FJ, Vivier E, Davis RS. FCRL6 distinguishes mature cytotoxic lymphocytes and is upregulated in patients with B-cell chronic lymphocytic leukemia. Eur J Immunol. (2008) 38:3159-66. doi: 10.1002/eji.200838516

47. Vivier E, Sorrell JM, Ackerly M, Robertson MJ, Rasmussen RA, Levine $\mathrm{H}$, et al. Developmental regulation of a mucinlike glycoprotein selectively expressed on natural killer cells. J Exp Med. (1993) 178:2023-33. doi: 10.1084/jem.178.6.2023

48. Angelini DF, Borsellino G, Poupot M, Diamantini A, Poupot R, Bernardi G, et al. FegammaRIII discriminates between 2 subsets of Vgamma9Vdelta2 effector cells with different responses and activation pathways. Blood. (2004) 104:1801-7. doi: 10.1182/blood-2004-01-0331

49. Appay V, Zaunders JJ, Papagno L, Sutton J, Jaramillo A, Waters A, et al. Characterization of CD4(+) CTLs ex vivo. J Immunol. (2002) 168:59548. doi: 10.4049/jimmunol.168.11.5954

50. Kulemzin SV, Zamoshnikova AY, Yurchenko MY, Vitak NY, Najakshin AM, Fayngerts SA, et al. FCRL6 receptor: expression and associated proteins. Immunol Lett. (2011) 134:174-82. doi: 10.1016/j.imlet.2010.09.023

51. Schreeder DM, Cannon JP, Wu J, Li R, Shakhmatov MA, Davis RS. Cutting edge: FcR-like 6 is an MHC class II receptor. J Immunol. (2010) 185:237. doi: $10.4049 /$ jimmunol.1000832

52. Baixeras E, Huard B, Miossec C, Jitsukawa S, Martin M, Hercend T, et al Characterization of the lymphocyte activation gene 3-encoded protein. A new ligand for human leukocyte antigen class II antigens. J Exp Med. (1992) 176:327-37. doi: 10.1084/jem.176.2.327

53. Huard B, Prigent P, Pages F, Bruniquel D, Triebel F. T cell major histocompatibility complex class II molecules down-regulate $\mathrm{CD} 4+\mathrm{T}$ cell clone responses following LAG-3 binding. Eur J Immunol. (1996) 26:11806. doi: $10.1002 /$ eji. 1830260533

54. Andrews LP, Marciscano AE, Drake CG, Vignali DA. LAG3 (CD223) as a cancer immunotherapy target. Immunol Rev. (2017) 276:80-96. doi: 10.1111/imr.12519

55. Wang J, Sanmamed MF, Datar I, Su TT, Ji L, Sun J, et al. Fibrinogenlike protein 1 Is a major immune inhibitory ligand of LAG-3. Cell. (2019) 176:334-47.e12. doi: 10.1016/j.cell.2018.11.010

56. Niehrs A, Garcia-Beltran WF, Norman PJ, Watson GM, Holzemer A, Chapel A, et al. A subset of HLA-DP molecules serve as ligands for the natural cytotoxicity receptor NKp44. Nat Immunol. (2019) 20:112937. doi: 10.1038/s41590-019-0448-4

57. Niehrs A, Altfeld M. Regulation of NK-cell function by HLA Class II. Fron Cell Infect Microbiol. (2020) 10:55. doi: 10.3389/fcimb.2020.00055

58. Ljunggren $\mathrm{HG}$, Karre $\mathrm{K}$. In search of the 'missing self': $\mathrm{MHC}$ molecules and NK cell recognition. Immunol Today. (1990) 11:237-44. doi: 10.1016/0167-5699(90)90097-S

59. Jiang YZ, Couriel D, Mavroudis DA, Lewalle P, Malkovska V, Hensel NF, et al. Interaction of natural killer cells with MHC class II: reversal of HLA-DR1-mediated protection of K562 transfectant from natural killer cell-mediated cytolysis by brefeldin-A. Immunology. (1996) 87:4816. doi: 10.1046/j.1365-2567.1996.483556.x

60. Weichold FF, Jiang YZ, Dunn DE, Bloom M, Malkovska V, Hensel NF, et al. Regulation of a graft-versus-leukemia effect by major histocompatibility complex class II molecules on leukemia cells: HLA-DR1 expression renders K562 cell tumors resistant to adoptively transferred lymphocytes in severe combined immunodeficiency mice/nonobese diabetic mice. Blood. (1997) 90:4553-8. doi: 10.1182/blood.V90.11.4553

61. Scrivener S, Goddard RV, Kaminski ER, Prentice AG. Abnormal T-cell function in B-cell chronic lymphocytic leukaemia. Leuk Lymphoma. (2003) 44:383-9. doi: 10.1080/1042819021000029993

62. Gorgun G, Holderried TA, Zahrieh D, Neuberg D, Gribben JG. Chronic lymphocytic leukemia cells induce changes in gene expression of CD4 and CD8 T cells. J Clin Invest. (2005) 115:1797-805. doi: 10.1172/JCI24176

63. Axelrod ML, Cook RS, Johnson DB, Balko JM. Biological consequences of MHC-II expression by tumor cells in cancer. Clin Cancer Res. (2019) 25:2392-402. doi: 10.1158/1078-0432.CCR-18-3200

64. Johnson DB, Estrada MV, Salgado R, Sanchez V, Doxie DB, Opalenik SR, et al Melanoma-specific MHC-II expression represents a tumour-autonomous phenotype and predicts response to anti-PD-1/PD-L1 therapy. Nat Commun. (2016) 7:10582. doi: 10.1038/ncomms 10582

65. Roemer MGM, Redd RA, Cader FZ, Pak CJ, Abdelrahman S, Ouyang $\mathrm{J}$, et al. Major histocompatibility complex class ii and programmed 
death ligand 1 expression predict outcome after programmed death 1 blockade in classic hodgkin lymphoma. J Clin Oncol. (2018) 36:94250. doi: 10.1200/JCO.2017.77.3994

66. Rodig SJ, Gusenleitner D, Jackson DG, Gjini E, Giobbie-Hurder A, Jin C, et al. MHC proteins confer differential sensitivity to CTLA-4 and PD1 blockade in untreated metastatic melanoma. Sci Transl Med. (2018) 10:aar3342. doi: 10.1126/scitranslmed.aar3342

67. Callahan MJ, Nagymanyoki Z, Bonome T, Johnson ME, Litkouhi B, Sullivan $\mathrm{EH}$, et al. Increased HLA-DMB expression in the tumor epithelium is associated with increased CTL infiltration and improved prognosis in advanced-stage serous ovarian cancer. Clin Cancer Res. (2008) 14:766773. doi: 10.1158/1078-0432.CCR-08-0479

68. Santa-Maria CA, Nanda R. Immune checkpoint inhibitor therapy in breast cancer. J Natl Compr Canc Netw. (2018) 16:125968. doi: 10.6004/jncen.2018.7046

69. Nanda R, Chow LQ, Dees EC, Berger R, Gupta S, Geva R, et al. Pembrolizumab in patients with advanced triple-negative breast cancer: phase Ib keynote-012 study. J Clin Oncol. (2016) 34:2460-7. doi: 10.1200/JCO.2015.64.8931

70. Park IA, Hwang SH, Song IH, Heo SH, Kim YA, Bang WS, et al. Expression of the MHC class II in triple-negative breast cancer is associated with tumor-infiltrating lymphocytes and interferon signaling. PLoS ONE. (2017) 12:e0182786. doi: 10.1371/journal.pone. 0182786

71. Forero A, Li Y, Chen D, Grizzle WE, Updike KL, Merz ND, et al. Expression of the MHC class II pathway in triple-negative breast cancer tumor cells is associated with a good prognosis and infiltrating lymphocytes. Cancer Immunol Res. (2016) 4:390-9. doi: 10.1158/2326-6066.CIR-15-0243

72. Loi S, Dushyanthen S, Beavis PA, Salgado R, Denkert C, Savas P, et al. RAS/MAPK activation is associated with reduced tumor-infiltrating lymphocytes in triple-negative breast cancer: therapeutic cooperation between MEK and PD-1/PD-L1 immune checkpoint inhibitors. Clin Cancer Res. (2016) 22:1499-509. doi: 10.1158/1078-0432.CCR-15-1125

73. Cancer Genome Atlas Research N, Weinstein JN, Collisson EA, Mills GB, Shaw KR, Ozenberger BA, et al. The cancer genome atlas pan-cancer analysis project. Nat Genet. (2013) 45:1113-20. doi: 10.1038/ng.2764

74. Cerami E, Gao J, Dogrusoz U, Gross BE, Sumer SO, Aksoy BA, et al. The cBio cancer genomics portal: an open platform for exploring multidimensional cancer genomics data. Cancer Discov. (2012) 2:4014. doi: 10.1158/2159-8290.CD-12-0095

75. Dieu-Nosjean MC, Antoine M, Danel C, Heudes D, Wislez M, Poulot $\mathrm{V}$, et al. Long-term survival for patients with non-small-cell lung cancer with intratumoral lymphoid structures. J Clin Oncol. (2008) 26:44107. doi: $10.1200 /$ JCO.2007.15.0284

76. Herbst RS, Soria JC, Kowanetz M, Fine GD, Hamid O, Gordon MS, et al. Predictive correlates of response to the anti-PD-L1 antibody MPDL3280A in cancer patients. Nature. (2014) 515:563-7. doi: 10.1038/nature14011
77. Tumeh PC, Harview CL, Yearley JH, Shintaku IP, Taylor EJ, Robert L, et al. PD-1 blockade induces responses by inhibiting adaptive immune resistance. Nature. (2014) 515:568-71. doi: 10.1038/nature13954

78. Remark R, Lupo A, Alifano M, Biton J, Ouakrim H, Stefani A, et al. Immune contexture and histological response after neoadjuvant chemotherapy predict clinical outcome of lung cancer patients. Oncoimmunology. (2016) 5:e1255394. doi: 10.1080/2162402X.2016.1255394

79. Robert C, Schachter J, Long GV, Arance A, Grob JJ, Mortier L, et al. Pembrolizumab versus ipilimumab in advanced melanoma. $N$ Engl J Med. (2015) 372:2521-32. doi: 10.1056/NEJMoa1503093

80. Robert C, Long GV, Brady B, Dutriaux C, Maio M, Mortier L, et al. Nivolumab in previously untreated melanoma without BRAF mutation. $N$ Engl J Med. (2015) 372:320-30. doi: 10.1056/NEJMoa1412082

81. Garon EB, Rizvi NA, Hui R, Leighl N, Balmanoukian AS, Eder JP, et al. Pembrolizumab for the treatment of non-small-cell lung cancer. N Engl J Med. (2015) 372:2018-28. doi: 10.1056/NEJMoa1501824

82. Rizvi NA, Mazieres J, Planchard D, Stinchcombe TE, Dy GK, Antonia SJ, et al. Activity and safety of nivolumab, an anti-PD-1 immune checkpoint inhibitor, for patients with advanced, refractory squamous non-small-cell lung cancer (CheckMate 063): a phase 2, single-arm trial. Lancet Oncol. (2015) 16:257-65. doi: 10.1016/S1470-2045(15)70054-9

83. Adams S, Gray RJ, Demaria S, Goldstein L, Perez EA, Shulman LN, et al. Prognostic value of tumor-infiltrating lymphocytes in triple-negative breast cancers from two phase III randomized adjuvant breast cancer trials: ECOG 2197 and ECOG 1199. J Clin Oncol. (2014) 32:295966. doi: 10.1200/JCO.2013.55.0491

84. Denkert C, von Minckwitz G, Darb-Esfahani S, Lederer B, Heppner BI, Weber $\mathrm{KE}$, et al. Tumour-infiltrating lymphocytes and prognosis in different subtypes of breast cancer: a pooled analysis of 3771 patients treated with neoadjuvant therapy. Lancet Oncol. (2018) 19:40-50. doi: 10.1016/S1470-2045(17) 30904-X

85. Emens LA, Cruz C, Eder JP, Braiteh F, Chung C, Tolaney SM, et al. Long-term clinical outcomes and biomarker analyses of atezolizumab therapy for patients with metastatic triple-negative breast cancer: a phase 1 study. JAMA Oncol. (2019) 5:74-82. doi: 10.1001/jamaoncol. 2018.4224

Conflict of Interest: RSD has filed a patent on FCRL6-specific antibodies and their use in immunotherapy.

Copyright (c) 2020 Davis. This is an open-access article distributed under the terms of the Creative Commons Attribution License (CC BY). The use, distribution or reproduction in other forums is permitted, provided the original author(s) and the copyright owner(s) are credited and that the original publication in this journal is cited, in accordance with accepted academic practice. No use, distribution or reproduction is permitted which does not comply with these terms. 